\title{
THE FATTY ACID COMPOSITION OF HUMAN THORACIC DUCT LYMPH LIPIDS *
}

\author{
By ROLF BLOMSTRAND AND OLLE DAHLBÄCK \\ (From the Srcedish Medical Research Council Unit for Biochemical Research Related to \\ Atherosclerosis, and the Department of Thoracic Surgery, University of Lund, \\ Sweden)
}

(Submitted for publication February 10, 1960; accepted March 11, 1960)

Fernandes, Van de Kamer and Weijers (1) in studying a child with chylothorax found that the pattern of the fatty acids in the chyle was influenced by the kind of fat fed, but significant differences between chyle and dietary fat always remained. Recent experiments with carboxyl-labeled fatty acids by Blomstrand and co-workers (2-4) indicate that the chyle triglycerides constitute the main transport form of ingested fatty acids in man. Detailed information about the influence of dietary fatty acids on the fatty acid composition of the different lipid classes of human chyle is, however, still lacking. Furthermore, in order to effectively evaluate studies on the postabsorptive metabolism of chylomicron fatty acids, it is necessary to ascertain the nature of the fatty acid components of the various chyle lipids of thoracic duct lymph.

Development of methods for obtaining thoracic duct lymph from human beings (5) and the analysis by gas-liquid chromatography (GLC) of the different lipids of human chyle after feeding a well defined triglyceride has made it possible to study the relationship between the fatty acid patterns of the different lymph lipid classes and the dietary fat.

\section{EXPERIMENTAL}

Experimental design. Patient $\mathrm{A}$ of this study was a 56 year old man with inoperable adenocarcinoma of the left lung. $\mathrm{He}$ was in good condition during the whole investigation. He was nourished for 6 days solely by an orally administered liquid formula (Table I) supplemented with vitamins and minerals (6). The daily intake of formula was divided into 5 equal portions fed at 7 and 10 a.m. and at 1,4 and 7 p.m. Tea or coffee was offered ad libitum. The fat in the formula diet consisted of a sterol-free triglyceride with fatty acid composition according to Table II.

* This work is part of the investigations supported by the Swedish Medical Research Council and the Scientific Council of the Swedish Dairies Association.
On the third day of the experimental period the thoracic duct was cannulated as described earlier (5) and the lymph was collected for a 10 minute period every hour during the next 36 hours. After that time the catheter was withdrawn without any untoward effect. On the fourth day of the experiment the first formula was fed at 7 a.m. and the rest of the day the formula was fed every third hour.

The lymph was collected for 10-minute periods in ethanol to prevent any enzymatic hydrolysis during the collection time. The feces were collected in ethanol and stored in an icebox until analyzed.

Patient B of this study was a 60 year old man with adenocarcinoma of the right lung. He was in good condition during the investigation and was fed a general mixed diet. The lymph sample analyzed was collected from the thoracic duct during the peak of fat absorption after feeding a fat-rich breakfast.

Extraction and fractionation of lymph lipids. The total lipids of the lymph were extracted with 20 volumes of ethanol: ether, $3: 1$. The solvent was evaporated in vacuo, and the total lipids were taken up in petroleum ether (bp 60 to $70^{\circ} \mathrm{C}$ ) and made up to volume. Aliquots were subjected to chromatography on silicic acid in order to obtain a neutral fat free fatty acid fraction and a phospholipid fraction $(7,8)$. The free fatty acids were then removed from the neutral fat by extraction with alkaline 50 per cent ethanol and re-extraction of the fatty acids with light petroleum after acidification. The neutral fat fraction (glycerides, cholesterol and cholesterol esters) were subjected to chromatography on silicic acid for separation of cholesterol esters and a triglyceride + cholesterol fraction (Table III).

TABLE I

Composition of liquid formula diet fed daily as sole source of nutrients to Patient $A^{*}$

\begin{tabular}{ll}
\hline \multicolumn{1}{c}{ Constituents } & Wt. \\
\hline & $g$ \\
Triglycerides, sterol-free & 210 \\
Milk protein & 470 \\
Dextrose & 670 \\
Water & 5,000
\end{tabular}

* The patient was fed $300 \mathrm{ml}$ five times a day; $1,500 \mathrm{ml}$ of this formula contains approximately 1,900 calories. 
TABLE II

The fatty acid patterns in human thoracic duct lymph lipids after feeding a well defined triglyceride in a liquid formula diet (Patient $A$ ) and sampling of the thoracic duct lymph during active fat absorption*

\begin{tabular}{|c|c|c|c|c|c|c|c|}
\hline \multirow[b]{2}{*}{ Fatty acid } & & \multirow{2}{*}{$\begin{array}{c}\text { Triglyceride } \\
\text { fed }\end{array}$} & \multicolumn{4}{|c|}{ Thoracic duct lymph lipids } & \multirow[b]{2}{*}{ Fecal FA } \\
\hline & & & TG & FFA & Ch.E. & $\overline{\mathrm{PL}}$ & \\
\hline & & $\%$ & $\%$ & $\%$ & $\%$ & $\%$ & $\%$ \\
\hline \multicolumn{8}{|l|}{ Saturated } \\
\hline $\begin{array}{l}\text { Lauric } \\
\text { Myristic } \\
\text { Pentadecanoic } \\
\text { Palmitic } \\
\text { Heptadecanoic } \\
\text { Stearic }\end{array}$ & $\begin{array}{l}12: 0 \\
14: 0 \\
15: 0 \\
16: 0 \\
17: 0 \\
18: 0\end{array}$ & $\begin{array}{c}1.0 \\
0.1 \\
18.3 \\
0.3 \\
3.0\end{array}$ & $\begin{array}{r}0.5 \\
16.4 \\
2.2\end{array}$ & $\begin{array}{r}3.6 \\
3.4 \\
4.0 \\
20.3 \\
9.2 \\
5.7\end{array}$ & $\begin{array}{r}0.3 \\
0.1 \\
\\
21.6 \\
0.2 \\
6.5\end{array}$ & $\begin{array}{r}0.4 \\
0.4 \\
23.1 \\
0.3 \\
14.6\end{array}$ & $\begin{array}{r}1.2 \\
2.0 \\
20.2 \\
1.0 \\
13.0\end{array}$ \\
\hline \multicolumn{8}{|l|}{ Monounsaturated } \\
\hline $\begin{array}{l}\text { Palmitoleic } \\
\text { Oleic }\end{array}$ & $\begin{array}{l}16: 1 \\
18: 1\end{array}$ & $\begin{array}{r}2.4 \\
74.2\end{array}$ & $\begin{array}{r}2.7 \\
70.4\end{array}$ & $\begin{array}{l}12.2 \\
19.5\end{array}$ & $\begin{array}{r}1.7 \\
58.7\end{array}$ & $\begin{array}{r}1.1 \\
32.4\end{array}$ & $\begin{array}{r}4.3 \\
48.2\end{array}$ \\
\hline \multicolumn{8}{|l|}{ Diunsaturated } \\
\hline Linoleic & $18: 2$ & 0.5 & 7.7 & 16.0 & 10.8 & 21.3 & 4.3 \\
\hline \multicolumn{8}{|l|}{ Polyunsaturated } \\
\hline $\begin{array}{l}\text { Linolenic } \\
\text { Arachidonic }\end{array}$ & $\begin{array}{r}18: 3 \\
20: 4 \\
20-22 ?\end{array}$ & & & & & $\begin{array}{l}0.5 \\
3.0 \\
2.4\end{array}$ & 2.8 \\
\hline Sum $\dagger$ & & 99.8 & 99.9 & 93.9 & 99.9 & 99.5 & 97.0 \\
\hline
\end{tabular}

* $\mathrm{TG}=$ triglyceride fatty acids, FFA = free fatty acids, Ch.E. = cholesterol ester fatty acids, PL = phospholipid fatty acids. The component fatty acids are also designated by a dual symbol giving chain length and number of double bonds. Values are expressed as percentage of total fatty acid methyl esters.

$\dagger$ The sum of each column is less than 100 per cent because trace amounts of unusual fatty acids detected were omitted from the final tabulation.

The lipids in aliquots of the test meals were extracted by the same method as that described for extraction of lymph lipids. Extraction was also made on the daily amount of wet feces with alcohol and ether as described earlier (9). The different lipid fractions were saponified and the fatty acids isolated as described previously (2). Methyl esters of the fatty acids were made by treating the fraction with a solution of diazomethane in ether. After standing, the ether and the diazomethane were carefully evaporated on the water bath. The methyl esters were dissolved in petroleum ether and stored in a refrigerator until analyzed.

The phospholipids were fractionated on silicic acid by the procedure described by Hanahan, Dittmer and Warashina (10). The loading ratio was $0.5 \mathrm{mg}$ of lipid phosphorus per $\mathrm{g}$ of silicic acid and the usual solvents were chloroform-methanol mixtures $(4: 1$ and $1: 4$, vol/vol, respectively). The progress of the chromatographic fractionation was followed by phosphorus assay and paper chromatography. The fractions containing lecithin were further rechromatographed on aluminium oxide (4) because the pure lecithin thus obtained reacted more satisfactorily with phospholipase A (Crotalus adamanteus venom).

Lecithin prepared from the lymph lipids of Patient A (Table IV) $(7.0 \mathrm{mg}$ of lipid P) was dissolved in $100 \mathrm{ml}$ of diethyl ether and treated with $2 \mathrm{mg}$ of snake venom
(Crotalus adamantcus) in $1 \mathrm{ml}$ of aqueous $0.1 \mathrm{M}$ calcium chloride solution. A fine stream of anhydrous ammonia was bubbled through the ether solution (11). A considerable amount of precipitate formed within two hours, and after four hours the solvent was removed by evaporation and reduced pressure. The residue was dissolved in chloroform and applied to a column of $5 \mathrm{~g}$ of silicic acid. Elution was continued with chloroform until all fatty acids released by phospholipase $A$ had been obtained. After removal of the solvent the methyl esters were prepared with diazomethane. Next, the column was eluted with chloroform: methanol $4: 1$ and $1: 4$, respectively, in order to separate unchanged lecithin from lysolecithin. The fatty acids of the lysolecithin were obtained after hydrolysis, acidification and extraction with light petroleum.

Analysis of fatty acid. GLC was carried out essentially as described by James and Martin (12) using an Argon Pye chromatograph with an ionization chamber as detector. The mobile phase (argon) was applied at a pressure of $72 \mathrm{~cm} \mathrm{Hg}$. Each four foot column was packed with acid-washed, alkali-treated celite 545 (mesh 120 to 140 ). As stationary phase, a polar polyester (LHC1R-296, obtained from Cambridge, Mass.) was used in the ratio celite: stationary phase, $4: 1$ (13). This column had a retention time of 10 minutes for methyl stearate. The retention volumes of the normal fatty 
TABLE III

Composition of thoracic duct lymph lipids of Patient $A$ after feeding a well defined triglyceride in a liquid formula diet and sampling of the thoracic duct lymph*

\begin{tabular}{|c|c|c|c|c|c|c|c|c|c|}
\hline \multirow[b]{2}{*}{ Patient } & \multirow[b]{2}{*}{$\begin{array}{c}\text { Collec- } \\
\text { tion } \\
\text { time }\end{array}$} & \multirow[b]{2}{*}{$\begin{array}{l}\text { Lymph } \\
\text { volume } \\
\text { per } \\
\text { minute }\end{array}$} & \multicolumn{3}{|c|}{ Total cholesterol fat } & \multicolumn{4}{|c|}{ Fatty acids as per cent of total fatty acids } \\
\hline & & & & Free & Total & $\begin{array}{l}\text { Choles- } \\
\text { terol } \\
\text { FA }\end{array}$ & FFA & $\begin{array}{c}\text { Triglyc- } \\
\text { eride } \\
\text { FA }\end{array}$ & $\begin{array}{c}\text { Phospho- } \\
\text { lipid } \\
\text { FA }\end{array}$ \\
\hline & $\min$ & $m l$ & $g \%$ & \multicolumn{2}{|c|}{$m g \%$} & & & & \\
\hline $\begin{array}{l}\text { A } \\
\text { B }\end{array}$ & $\begin{array}{l}10 \\
10\end{array}$ & $\begin{array}{l}2.0 \\
1.6\end{array}$ & $\begin{array}{l}4.4 \\
4.7\end{array}$ & $\begin{array}{l}35 \\
44\end{array}$ & $\begin{array}{l}80 \\
95\end{array}$ & $\begin{array}{l}1.3 \\
1.6\end{array}$ & $\begin{array}{l}2.7 \\
2.1\end{array}$ & $\begin{array}{l}86.0 \\
85.5\end{array}$ & $\begin{array}{l}11.0 \\
10.6\end{array}$ \\
\hline
\end{tabular}

* The thoracic duct lymph was collected for 10-minute periods every hour during 36 hours. The lymph sample analyzed was collected at $11 \mathrm{a} . \mathrm{m}$. on the fourth day of the experiment. Patient B was on a free diet during the collection period at 11 a.m.

acids were determined using a mixture of pure esters of fatty acids obtained from the Hormel Institute (Austin, Minn.). Major acids were identified by comparison with the retention volumes of these pure standards. For identification the samples were also chromatographed at $240^{\circ} \mathrm{C}$ on a column with silicone oil (Dow-Corning high vacuum grease) as stationary phase in the ratio celite: silicone oil, 4:1. For determination of branched and unsaturated fatty acid, the samples were also run after hydrogenation.

In this report fatty acids are numbered as suggested by Insull, Hirsch, James and Ahrens (14). Thus 18:0 refers to the straight chain saturated $\mathrm{C}_{18}$ acid, stearic, 18:2 $=\mathrm{C}_{18}$-diene and so forth.

Results were computed by the triangulation method.

\section{RESULTS}

Table III permits comparison of the analytical data for the dietary triglyceride fatty acids with the figures for the different lipid classes of the thoracic duct lymph. The lymph sample analyzed was collected four hours after feeding the first test meal at 7 a.m. on the fourth day of the experiment. The fecal fatty acids are from the stools collected on the fifth day of the experimental period. Data derived from analysis of fecal lipids are also shown.

Lymph cholesterol esters. The fatty acids found in the ester linkage with a lymph cholesterol were chiefly oleic acid, 58.7 per cent, and palmitic acid, 21.6 per cent. The concentrations of these fatty acids are very similar in the dietary triglyceride and the lymph cholesterol esters. Stearic acid, 6.5 per cent, and linoleic acid, 19.8 per cent, were both found in higher concentration than in the dietary triglyceride.

Lymph triglycerides. The fatty acid composition of the lymph triglycerides is almost exactly the same as that in the fed triglyceride. Oleic acid, constituting 74.4 per cent of the fed triglyceride, is found in the high concentration of 70.2 per cent in the lymph triglycerides. Palmitic and stearic acid also have almost the same concentration in the lymph triglycerides as in the diet. A remarkable difference is the higher concentration of linoleic acid, 7.7 per cent in the lymph triglycerides compared with 0.5 per cent in the diet.

Phospholipid fatty acids. The composition of the phospholipid fatty acids is different from that of the dietary triglycerides, and the triglycerides and the cholesterol esters of the lymph. The major acids are oleic acid, 32.4, stearic acid, 14.6, and linoleic acid, 21.3 per cent. The major component of the lymph phospholipids is lecithin. A similar fatty acid composition has been described earlier for human lecithin on a general mixed diet (4).

In Experiment $\mathrm{A}$ the lymph lecithin was isolated and the fatty acids freed by phospholipase A were determined with GLC (Table IV). In this fraction 85 per cent of the total fatty acids were unsaturated fatty acids. On the other hand, in the fatty acids isolated from the lysolecithin, 67 per cent of the total fatty acids were saturated. In the fatty acids released by phospholipase $A$, the three major fatty acids were palmitic, 15.9, oleic, 24.2, and linoleic acid, 34.7 per cent. Small amounts of myristic, pentadecanoic and stearic acid were also present, as well as palmitoleic, linolenic and arachidonic acid.

Two fatty acids with 20 to 22 carbon atoms were present on the gas chromatogram. In the lysolecithin the three major fatty acids were palmitic, 33.2 stearic 26.8 and oleic acid, 25.2 per 
TABLE IV

The fatty acid composition of human thoracic duct lymph lecithin (Patient A) after feeding a well defined triglyceride in a liquid formula diet*

\begin{tabular}{|c|c|c|c|}
\hline \multirow[b]{2}{*}{ Fatty acid } & & \multicolumn{2}{|c|}{$\begin{array}{l}\text { Percentage of total fatty acids in respective } \\
\text { positions of human lymph lecithin }\end{array}$} \\
\hline & & $\begin{array}{l}\text { Fatty acids freed } \\
\text { from lymph lecithin } \\
\text { by phospholipase A }\end{array}$ & $\begin{array}{l}\text { Fatty acids obtained } \\
\text { after hydrolysis of } \\
\text { lysolecithin }\end{array}$ \\
\hline \multicolumn{4}{|l|}{ Saturated } \\
\hline $\begin{array}{l}\text { Myristic } \\
\text { Pentadecanoic } \\
\text { Palmitic } \\
\text { Heptadecanoic } \\
\text { Stearic }\end{array}$ & $\begin{array}{l}14: 0 \\
15: 0 \\
16: 0 \\
17: 0 \\
18: 0\end{array}$ & $\begin{array}{r}0.7 \\
0.5 \\
15.9 \\
0.3 \\
8.6\end{array}$ & $\begin{array}{r}0.8 \\
0.8 \\
33.1 \\
0.8 \\
26.8\end{array}$ \\
\hline \multicolumn{4}{|l|}{ Monounsaturated } \\
\hline $\begin{array}{l}\text { Palmitoleic } \\
\text { Oleic }\end{array}$ & $\begin{array}{l}16: 1 \\
18: 1\end{array}$ & $\begin{array}{r}1.6 \\
24.2\end{array}$ & $\begin{array}{r}4.7 \\
25.2\end{array}$ \\
\hline \multicolumn{4}{|l|}{ Diunsaturated } \\
\hline Linoleic & $18: 2$ & 34.7 & 3.7 \\
\hline \multicolumn{4}{|l|}{ Polyunsaturated } \\
\hline $\begin{array}{l}\text { Linolenic } \\
\text { Arachidonic }\end{array}$ & $\begin{array}{r}18: 3 \\
20: 4 \\
20-22 ?\end{array}$ & $\begin{array}{l}1.0 \\
6.1 \\
4.4\end{array}$ & \\
\hline Sum $\dagger$ & & 98.0 & 95.9 \\
\hline
\end{tabular}

* The lecithin was purified by silicic acid column chromatography and hydrolyzed with phospholipase A. For explanation of symbols see Table II.

$\dagger$ The sum of each column is less than 100 per cent because trace amounts of unusual fatty acids detected were omitted from the final tabulation.

cent: Small amounts of palmitoleic and linoleic acid were also present.

The composition of the lymph phospholipid fatty acids is apparently not influenced to any high degree by the fed dietary fatty acids.

Free fatty acids $(F F A)$. This fraction was obtained from the human thoracic duct lymph after isolation of a neutral fat plus FFA fraction from the phospholipids on silicic acid. The FFA were then extracted with alkaline 50 per cent ethanol and recovered into light petroleum after acidification.

The major FFA in both experiments was palmitic acid comprising 20.3 and 24.6 per cent, respectively. In Experiment A oleic acid constituted only 19.5 per cent compared with 74.2 per cent in the diet. An interesting finding was the relatively high percentage of palmitoleic acid in both experiments, 12.2 and 18.6, respectively. In Experiment $B$ there was more palmitoleic acid than oleic acid in the FFA. In both experiments there was a clear tendency to higher concentrations of fatty acids with 10 to 15 carbon atoms in the free fraction.
In Table $\mathrm{V}$ the results of the analyses of the lymph lipids obtained from Patient B are shown. This patient was fed a general mixed diet during the whole experimental period. From the analytical data in Table $\mathrm{V}$ it is apparent that the three lymph lipid classes analyzed have three distinctly different fatty acid patterns.

The three major components of the lymph triglycerides are myristic, palmitic and oleic acid. Oleic acid is, however, not so predominant as in the experiment with Patient $A$, in which the major component in the fed triglyceride was oleic acid.

The general picture of fatty acid pattern of the lymph phospholipids was similar in the two patients, but there were slight differences in the percentages of some of the components present. In particular, the lymph phospholipids of Patient $B$ contained more linoleic acid.

Regarding the fecal fatty acids analyzed from Patient A, significant differences can be found between the fed composition of the fed fatty acids and the fecal fatty acids. The diet was very well absorbed and from earlier experiments (1) it can be expected that about 50 per cent of the fecal 
TABLE $\mathbf{V}$

The fatty acid patterns in human thoracic duct lymph lipids of Patient $B$ after feeding a general mixed diet and sampling of the thoracic duct lymph during active fat absorption*

\begin{tabular}{|c|c|c|c|c|c|}
\hline \multirow[b]{2}{*}{ Fatty acid } & & \multicolumn{4}{|c|}{ Thoracic duct lymph lipids } \\
\hline & & TG & \multirow{2}{*}{$\begin{array}{c}\text { FFA } \\
\%\end{array}$} & \multirow{2}{*}{$\begin{array}{c}\text { Ch.E. } \\
\%\end{array}$} & PL \\
\hline Saturated & & $\%$ & & & $\%$ \\
\hline Decanoic & $10: 0$ & & 1.4 & & \\
\hline $\begin{array}{l}\text { Undecanolc } \\
\text { Lauric }\end{array}$ & $\begin{array}{l}11: 0 \\
12: 0\end{array}$ & 2.8 & $\begin{array}{l}1.1 \\
2.6\end{array}$ & & 2.2 \\
\hline Myristic & $14: 0$ & 11.9 & 5.0 & & 7.3 \\
\hline Pentadecanoic & $15: 0$ & 1.8 & 2.0 & & 1.2 \\
\hline Palmitic & $16: 0$ & 24.6 & 24.6 & & 35.4 \\
\hline Heptadecanoic & $17: 0$ & 1.0 & 2.7 & & \\
\hline Stearic & $18: 0$ & 6.1 & 8.8 & & 13.3 \\
\hline Monounsaturated & & & & & \\
\hline Myristoleic & $14: 1$ & & 4.7 & & \\
\hline Palmitoleic & $16: 1$ & 5.0 & 18.6 & & 6.5 \\
\hline Oleic & $18: 1$ & 31.6 & 16.1 & & 25.1 \\
\hline & 18:1 & & 4.2 & & \\
\hline \multicolumn{6}{|l|}{ Diunsaturated } \\
\hline Linoleic & $18: 2$ & 8.6 & 6.5 & & 6.5 \\
\hline \multicolumn{6}{|l|}{ Polyunsaturated } \\
\hline Linolenic & $\begin{array}{r}18: 3 \\
20-22 ?\end{array}$ & $\begin{array}{l}0.8 \\
1.8\end{array}$ & & & \\
\hline Sum $t$ & & 96.0 & 98.3 & & 97.5 \\
\hline
\end{tabular}

* For explanation of symbols see Table II. Values are expressed as percentage of total fatty acid methyl esters.

$\dagger$ The sum of each column is less than 100 per cent because trace amounts of unusual fatty acids detected were omitted from the final tabulation.

fatty acids are of dietary origin. The fecal fatty acids are somewhat more saturated and they contain significantly more stearic acid, which may in part originate from hydrogenated oleic acid in the diet (15). Especially interesting is the presence of fatty acids with 20 to 22 carbon atoms. The exact nature of these fatty acids has not yet been determined. Analyses of human bile (16) have revealed the presence of fatty acids belonging to the $\mathrm{C}_{20}$ and $\mathrm{C}_{22}$ groups in the bile lipids.

\section{DISCUSSION}

Although the fatty acid composition of the total fat of human chyle was determined earlier (1), there has been little information reported until recently (4) on the composition of the individual lipids of human thoracic duct lymph. Dole and associates (17) have reported the fatty acid composition of human chylomicra in plasma during fasting and alimentary lipemia. It was found that neither the chylomicra nor any other fractions acquired the pattern of dietary fat during the period of lipemia. As is apparent from the re- sults of this investigation (Table II) the fatty acids of the lymph triglycerides acquired very rapidly the patterns of dietary fat during the absorption process. The triglyceride fatty acids of human chyle constitute approximately 85 per cent of the total fatty acids of chyle, and the relative stability of the plasma fatty acid reported during absorption (17) must depend on a rapid removal of the chylomicron fatty acids, presumably by the liver, and recycling of fatty acids between blood and tissue pools.

It is of interest to note that the FFA pattern of the human thoracic duct lymph did not follow changes in the triglyceride pattern, nor was it influenced by the fed fat. Apparently this fraction was not derived from lipolysis of the lymph triglycerides. This fraction may represent the sum of albumin-bound FFA originating from serum as well as FFA derived from the fat depots drained by the lymph. These results also confirm other experiments in rats (18) and in man (2).

The fatty acid composition of the cholesterol esters was highly influenced by the dietary tri- 
glyceride as shown by the high percentage of oleic acid (Table II). Apparently dietary fatty acids are used for esterification of cholesterol during the absorption process. In view of recent studies of the effects of unsaturated and saturated fatty acids on serum cholesterol levels (19) and the demonstration that cholesterol excretion by intestine is in part controlled by the composition of the dietary fat (20), the finding in this investigation of a dietary effect on the fatty acid composition of the lymph cholesterol esters might have some bearing on the direct control of the absorption of cholesterol. Different fatty acids might influence the absorption of endogenous and dietary cholesterol from the intestine in such a significant way that the effects of dietary fatty acids on the serum cholesterol might be mainly an absorption effect. It will be of interest to continue these studies with comparison of variously constituted dietary fats on the absorption of cholesterol in patients with thoracic duct fistula.

In the lymph phospholipids the fatty acid composition was not influenced to any significant degree by the dietary fat. The fatty acid composition of the lymph phospholipids was in fact very similar in the two experiments, in spite of the different diet fed. Most of the phospholipids of the lymph represent endogenous phospholipids in agreement with previous experiments in animals (21) and in man $(2,4)$.

According to a recent work by Tattrie (22) the site of the attack of phospholipase A should be at the C-2 (beta) position instead of at the C-1 (alpha) position as has been proposed by Hanahan (23). According to this new concept the unsaturated fatty acids predominated in the C-2 (beta) ester position, although saturated fatty acids such as myristic, palmitic and stearic acid were also isolated from this position. In the C-1 (alpha) position saturated fatty acids predominated but oleic acid constituted the same percentage of the total fatty acids in both positions (4). A small amount of palmitoleic and linoleic acid was also obtained in the C-1 position. Apparently there is an asymmetrical distribution of many fatty acids in the human lymph lecithins. This asymmetrical distribution is, however, not obligatory, as can be seen from the finding that oleic acid is distributed almost equally between the C-1 (alpha) and the C-2 (beta) positions. A similar distribution pattern for oleic acid has recently been obtained in liver lecithins of rat (24). Apparently there are several different lecithins present in the lymph and for a more explicit understanding of their metabolism it is necessary to isolate the individual species. The pronounced positional asymmetry of the fatty acids of the lecithin molecules of the lymph also indicates that for complete elucidation of the metabolic pathways of the different fatty acids during the absorption process the positional location of the individual fatty acid on both phospholipids and triglycerides must be considered.

\section{SUMMARY}

1. Analyses were made of the fatty acid composition of the lipid components of human thoracic duct lymph by gas liquid chromatography.

2. The fatty acid distribution in the lymph triglycerides and the cholesterol esters was largely influenced by the dietary fat. The free fatty acids had quite another pattern than did the lymph triglycerides and were not influenced by the dietary fat.

3. The phospholipid fatty acids were influenced very little by the dietary fat. An asymmetrical distribution of the fatty acids of the lymph lecithins uninfluenced by the fat fed is described.

\section{REFERENCES}

1, Fernandes, J., Van de Kamer, J. H., and Weijers, H. A. The absorption of fats studied in a child with chylothorax. J. clin. Invest. 1955, 24, 1026.

2. Blomstrand, R., and Ahrens, E. H., Jr. The absorption of fats studied in a patient with chyluria. J. biol. Chem. 1958, 233, 321.

3. Blomstrand, R., Dahlbäck, O., and Linder, E. Asymmetric incorporation of linoleic acid-1-C $\mathrm{C}^{\mathbf{1 4}}$ and stearic acid-1-C $\mathrm{C}^{\mathbf{1 4}}$ into human lymph lecithins during fat absorption. Proc. Soc. exp. Biol. (N. Y). 1959, 100, 768.

4. Blomstrand, R., and Dahlbäck, O. Gas-liquid chromatography of human lymph fatty acids after feeding $\mathrm{C}^{\mathbf{1 4}}$-labelled fats. Acta Soc. Med. upsalien. 1959, 64, 177.

5. Linder, E., and Blomstrand, R. Technic for collection of thoracic duct lymph of man. Proc. Soc. exp. Biol. (N. Y.) 1959, 97, 653.

6. Ahrens, E. H., Jr., Dole, V. P., and Blankenhorn, D. H. The use of orally-fed liquid formulas in metabolic studies. Amer. J. clin. Nutr. 1954, 2, 336.

7. Borgström, B. Investigation on lipid separation 
method. Separation of phospholipids from neutral fat and fatty acids. Acta physiol. scand. 1952, 25, 102 .

8. Borgström, B. Investigation on lipid separation methods. Separation of cholesterol esters, glycerides and free fatty acids. Acta physiol. scand. 1952, 25, 111.

9. Blomstrand, R. A study on the intestinal absorption of fat in normal adults and in non-tropical sprue with carbon-labelled oleic and palmitic acid. Acta med. scand. $1955,152,1$.

10. Hanahan, D. J., Dittmer, J. C., and Warashina, E. A column chromatographic separation of classes of phospholipides. J. biol. Chem. 1957, 228, 685.

11. Long, C., and Penny, I. F. The structure of naturally occurring phosphoglycerides. III. Action of moccasin-venom phospholipase A on ovolecithin and related substances. Biochem. J. 1957, 65, 382.

12. James, A. T., and Martin, A. J. P. Gas-liquid partition chromatography: The separation and microestimation of volatile fatty acids from formic acid to duodeconic acid. Biochem. J. 1952, 50, 679.

13. Orr, C. H., and Callen, J. E. Recent advances in the gas chromatographic methyl esters of fatty acids. Ann. N. Y. Acad. Sci. 1959, 72, 649.

14. Insull, W., Jr., Hirsch, J., James, T., and Ahrens, E. H., Jr. The fatty acids of human milk. II. Alterations produced by manipulation of caloric balance and exchange of dietary fats. J. clin. Invest. $1959,38,443$.

15. Bergström, S., and Blomstrand, R. Studies on the intestinal absorption of fat in man with the aid of labelled oleic and palmitic acid in Biochemical Problems of Lipids (Proc. Soc. Int. Conf. Ghent, 1955). London, Butterworth, 1956, p. 323.

16. Blomstrand, R. Analysis of human bile lipids by gas-liquid chromatography. Acta chem. scand. In press.

17. Dole, V. P., James, A. T., Webb, J. P. W., Rizack, M. A., and Sturman, M. F. The fatty acid patterns of plasma lipids during alimentary lipemia. J. clin. Invest. 1959, 38, 1544.

18. Borgström, B., and Tryding, N. Free fatty acid content of rat thoracic duct lymph during fat absorption. Acta physiol. scand. 1956, 37, 127.

19. Ahrens, E. H., Jr., Insull, W., Jr., Blomstrand, R., Hirsch, J., Tsaltas, T., and Peterson, M. L. The influence of dietary fats on serum lipid levels in man. Lancet 1957, 272, 943.

20. Hellman, L., Rosenfeld, R. S., Insull, W., Jr., and Ahrens, E. H., Jr. Intestinal excretion of cholesterol: A mechanism for regulation of plasma levels (abstract). J. clin. Invest. 1957, 36, 898.

21. Bergström, S., Blomstrand, R., and Borgström, B. Route of absorption and distribution of oleic acid and triolein in the rat. Biochem. J. 1954, 58, 600.

22. Tattrie, N. H. Positional distribution of saturated and unsaturated fatty acids on egg lecithin. J. Lip. Res. 1959, 1, 60.

23. Hanahan, D. J. The site of action of lecithinase A of lecithin. J. biol. Chem. 1954, 207, 879.

24. Dittmer, J. C., and Hanahan, D. J. Biochemistry of long chain fatty acids. 1. General observations. J. biol. Chem. 1959, 234, 1976. 